\title{
OS SOLOS DE UMA TOPOSSEQÜÊNCIA NA ILHA DE ALGODOAL/ MAIANDEUA, NORDESTE DO ESTADO DO PARÁ, BRASIL: COMPOSIÇÃO QUIIMICA E PRODUÇÃO DE MATÉRIA ORGÂNICA ${ }^{(1)}$
}

\author{
Maria de Lourdes P. RUIVO ${ }^{(2)}$, Idême Gomes AMARAL ${ }^{(2)}$, Elton Luciano da C. RIBEIRO( ${ }^{(3)}$, \\ André Luis Santos GUEDES ${ }^{(3)}$
}

\begin{abstract}
RESUMO - O estudo foi realizado na Ilha de Algodoal/Maiandeua no nordeste do Estado do

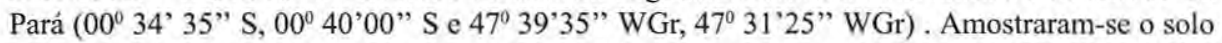
e a matéria orgânica leve, nas profundidades de $0-5 \mathrm{~cm}, 5-10 \mathrm{~cm}$ e $10-20 \mathrm{~cm}$, e a manta orgânica ao longo de uma toposseqüência com solos e cobertura vegetal diversificados. Não foram verificadas diferenças estatisticas entre os componentes quimicos da fração ácido fúlvico nos solos estudados.
\end{abstract}

Palavras-chave: Solos Litoraneos, Gênese de Solos, Área de Proteção Ambiental

The Soils of a Toposequence in the Algodoal/Mainadeua Island, Para State, Brazil: Chemical Composition and Organic Matter Production.

ABSTRACT - This paper shows the results of a survey in Algodoal/Mainadeua Island, Pará

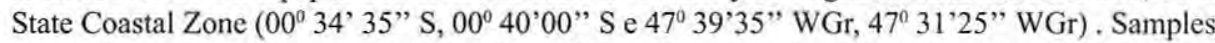
were colleted from the organic surface layer (litter), light organic matter and soil (depths $0-5 \mathrm{~cm}$, $5-10 \mathrm{~cm}$ and $10-20 \mathrm{~cm}$ ) along a toposequence with diversified soils and vegetation cover. There were no statistical differences between the chemical components of the fulvic acid fraction in the soils ander study.

Key-words: Coastal Soil, Soil Geneis, Environmetal Protection Area

\section{Introdução}

A área estuarina do Estado do Pará é importante do ponto de vista ambiental, comercial e de ecoturismo. Uma das áreas de maior importância, seja do ponto de vista ambiental ou de ecoturismo é a Ilha de Maiandeua, uma área de proteção ambiental (APA), localizada no nordeste paraense (Fig. 1). Estudos geoambientais estão sendo realizados pelo Museu Paraense Emílio Goeldi (MPEG), dentro do Programa de Estudos Costeiros (PEC), a fim de estabelecer, entre outros objetivos, indicadores de sustentabilidade deste ecossistema.

Um dos indicadores mais usados na avaliação da sustentabilidade dos ecossistemas terrestres é a matéria orgânica do solo (MOS), seja ela lábil (residuos de plantas, formas orgânicas solúveis em água, matéria orgânica leve, biomassa microbiana e outras) ou estável (substâncias húmicas e outras). A MOS pode ser caracterizada pela análise dos seus componentes lábeis (não húmicos) e não lábeis (húmicos), os quais são os maiores reservatórios terrestres de carbono orgânico (Zeck et al., 1997). A fração leve da matéria orgânica (MOL) constitui-se, principalmente de residuos de plantas, porém resíduos de animais e microorganismos também podem estar presente em vários estágios de decomposição. Segundo Theng et al. (1989) esta fração pode conter 10-30\% do $\mathrm{C}$ do solo. A MOL tem sido útil na

\footnotetext{
'Apoio Financeiro FUNTEC/SECTAN

2Pesquisador, Departamento de Ecologia/MPEG e-mail: ruivo@museu-goeldi.br

${ }^{3}$ Bolsista de Iniciação Científica, Departamento de Ecologia/MPEG
} 
caracterização da sustentabilidade e, considerada MOS. Por sua ou recuperação de áreas degradadas importância na ciclagem de nutrientes (Ruivo, 1998 e Duda et al., 1999). e formação de húmus, esta camada é A manta orgânica (MO), por considerada como parte integrante do recobrir a superfície do solo, não é perfil do solo. A taxa de decomposição

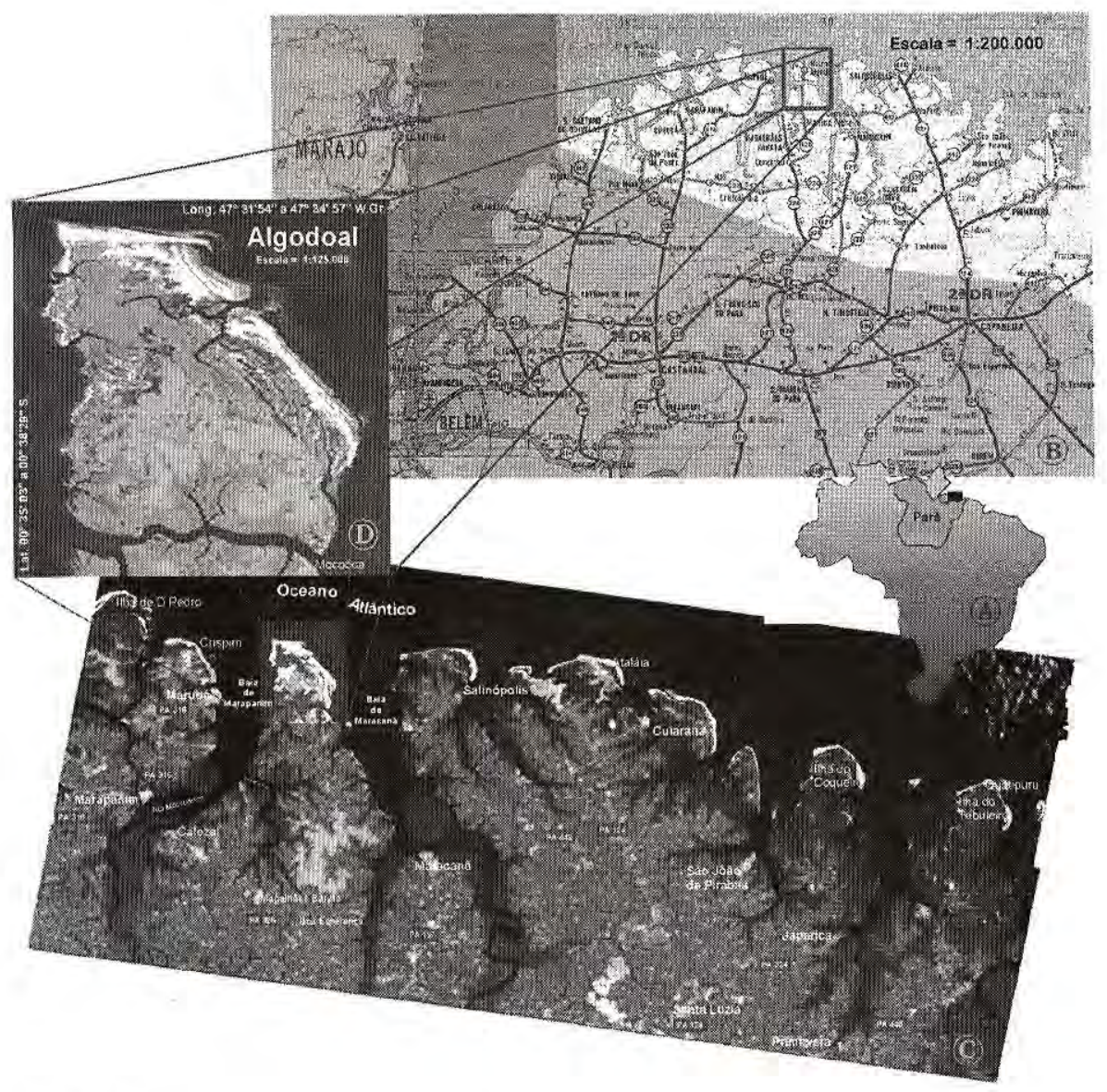

Legenda:

(A) Situação do Litoral NE do Pará em relação ao país.

(B) Situação da liha de Algodoal-Maiandeua em relação ao Litoral NE do Pará.

(C) Litoral NE do Pará (Composiçăo colorida, bandas 3R 4G 5B, obtida pelo Satélite LANDSAT TM5 em Julho/1988).

(10) Detalhe da liha Algodoal-Maiandeua, mostrando os ecossistemas dominantes.

Figura 1. Ilha de Maiandeua 
da MO varia em função da qualidade do material vegetal e do teor de lignina (Anderson e Flanagan, 1994). Nos ecossistemas florestais pode está de acordo com a abundância, atividade e composição dos organismos do solo. Sales (2000), estudando a decomposição de folhas no estuário paraense, verificou que a diferença na composição florística não foi fator determinante na velocidade de decomposição dos tecidos vegetais e sim as características físicoquímicas das folhas.

Durante os processos de decomposição microbiológica da matéria orgânica ocorre a formação de compostos de natureza heterogenea e complexa, denominadas "substâncias húmicas", onde podem-se citar os ácidos húmicos, fúlvicos, himatomelânicos e huminas (Toledo, 1979). $\mathrm{O}$ fato das substâncias húmicas $(\mathrm{SH})$ possuirem propriedades diferenciadas permite o seu estudo individualizado, especialmente das frações de ácidos fúlvicos e húmicos (Ceretta, 1996). A MOS tem papel fundamental na qualidade do solo, pois atua como reserva de nutrientes para a biota, como fonte de $\mathrm{C}$, $\mathrm{n} \mathrm{PeS}$ e outros nutrientes requeridos pelas plantas. Influencia o $\mathrm{pH}$, a troca de cátions e aniôns e, também, as propriedades fisicas dos solos, tais como a agregação, porosidade e retenção de água (Gregorich et al., 1994; Kononova, 1966).

Este trabalho teve como objetivo apresentar os resultados preliminares da caracterização ds substâncais húmicas (AH e $\mathrm{AF})$, as produções de manta orgânica e matéria orgânica leve, e suas relações com cada tipo de solo, em uma toposseqüência na Ilha de Maiandeua/Pará.

\section{Material e Métodos}

\section{Caracterização da Área:}

$\mathrm{O}$ estudo foi realizado na Área de Proteção Ambiental (APA) da Ilha de Algodoal/Maiandeua localizada na Zona Costeira do Estado do Pará (Fig. 1). O clima regional pode ser enquadrado como tropical quente e úmido, com médias anuais de temperatura em torno de $27,7^{\circ} \mathrm{C}$ e precipitação em torno de $3000 \mathrm{~mm} /$ ano. A distribuição de chuvas ao longo dos meses define dois períodos distintos: um chuvoso, que se estende de dezembro a maio; e um período de estiagem nos demais meses do ano.

A vegetação que predomina na ilha é a restinga (Bastos, 1996). A intervenção antrópica, porém, tem modificado bastante essa paisagem natural cedendo lugar à formações secundárias (capoeiras) e a introdução de pastagens e culturas de subsistência, especialmente mandioca. Os perfis descritos para esse estudo, situados ao longo de um transecto, foram caracterizados morfológica, física, química, mineralogicamente e classificados por Amaral et al.(2000) como Argissolo Amarelo Distrófico, Espodossolo Hidromórfico, Neossolo Flúvico e Neossolo Flúvico Sódico (designado localmente de apicum, que é um termo popular que designa solo salino maiores detalhes em Amaral, 1998).

\section{Metodologia de Coleta e} Análises:

Amostras compostas de solo a partir de cinco amostras simples, com 
03 repetições foram coletadas em 6 perfis de solos (Tab. 1) nas profundidades de $0-5 \mathrm{~cm}, 5-10 \mathrm{~cm}$ e 10 $20 \mathrm{~cm}$, situados ao longo de uma toposseqüência com cerca de $1370 \mathrm{~m}$ de extensão. A descrição morfológica e a classificação dos solos constam em Amaral et al. (2000).

Após transformadas em terra fina seca ao ar, subamostras foram conservadas em geladeira a $4^{\circ} \mathrm{C}$. Foram determinados o índice de acidez, teores de carbono orgânico, fósforo disponivel e os cátions trocáveis $(\mathrm{Ca}, \mathrm{Mg}$, Na e K (EMBRAPA, 1997). Realizouse a extração dos ácidos orgânicos e subseqüêntemente a separação dos ácidos: ácido fúlvico $(\mathrm{AF})$ e ácido húmico (AH) (Costa , 1992).

A manta orgânica (MO) foi coletada em parcelas de $0,30 \times 0,30 \mathrm{~m}$, cada amostra composta por cinco amostras simples, com três repetições, coletadas próximo aos locais onde foram amostrados os solos. A determinação da produção de matéria orgânica leve (MOL) foi realizada a partir de cinco amostras simples, com três repetições, coletadas nas profundidade citadas anteriormente. A parte mineral foi separada da parte orgânica por flotação em água com auxilio de tamis de $0,25 \mathrm{~mm}$ e submetidas a seis lavagens consecutivas. Ambas foram secas em estufa, a $68^{\circ} \mathrm{C}$ por $48 \mathrm{~h}$ para obtenção do peso da matéria seca e analisadas quimicamente para alguns macro $(\mathrm{Ca}$, $\mathrm{K}, \mathrm{Mg}$ ) e micronutrientes ( $\mathrm{Fe}, \mathrm{Zn}$ e $\mathrm{Cu}$ ) (EMBRAPA, 1997).

Os resultados das análises do AF foram analisados estatisticamente através do teste de Student ao nivel de $5 \%$ de probabilidade.

\section{Resultados e Discussão}

A MOL diminuiu em profundidade atingindo valores muito baixos em alguns perfis. Os sitios 4 e 4A (Espodossolo Hidromórfico), apresentaram maiores quantidades de MOL nas três profundidades, também, apresentaram as maiores quantidades de MO. A análise das características químicas dos solos na toposseqüência mostra que os perfis $4 \mathrm{e}$ 4A também apresentaram, em geral, teores de $\mathrm{C}, \mathrm{N}, \mathrm{P}$ mais elevados que os demais (Tab. 2), estimando-se assim uma maior mineralização da matéria orgânica.

Os teores de $\mathrm{Na}, \mathrm{K}$ e $\mathrm{Mg}$, nos três compartimentos estudados (solo,

Tabela 1. Classes de solos, cobertura vegetal e superfície geomorfológica

\begin{tabular}{llll}
\hline Sítio & Solo & Cobertura Vegetal & Superfície Geomorfológica \\
\hline 3 & NEOSSOLO FLÚVICO Sódico (Apicum) & Gramínea & Planície Costeira Baixa \\
4 & ESPODOSSOLO HIROMÓRFICO & Restinga & Planície Arenosa \\
$4 a$ & ESPODOSSOLO HIROMÓRFICO & Restinga & Planície Arenosa \\
5 & ARGISSOLO AMARELO Distrófico & Restinga & Baixo Planalto Costeiro \\
$5 a$ & NEOSSOLO FLÚVICO & Restinga & Baixo Planalto Costeiro \\
6 & NEOSSOLO FLÚVICO & Secundária & Baixo Planalto Costeiro \\
\hline
\end{tabular}


MOL e MOG), foram, em geral, mais elevados no sítio do Neossolo Flúvico Sódico (Apicum), conferindo a este substrato uma alta salinidade (Prost, 1994), pois está sujeito à influência da maré. Estes altos teores de bases também conferem ao solo características de $\mathrm{pH}$ moderadamente ácido (Tab. 2).

Os nutrientes mais ligados à cobertura vegetal, como $\mathrm{C}$ e $\mathrm{P}$ e, também, o Ca foram mais elevados nos sítios 4, 5 e 3 (Tab. 2). O sítio 3 é o Apicum, com cobertura vegetal de gramínea, que possui um vasto enraizamento. Isto faz com que o solo tenha mais $\mathrm{C}$ e $\mathrm{P}$ derivados da decomposição deste material. Nos sítios 4 (Espodossolo Hidromórfico) e 5 (Argissolo Amarelo Distrófico), ambos sob vegetação de restinga, estes nutrientes são oriundos da cobertura vegetal e dos tecidos da biomassa microbiana (resultados não apresentados neste trabalho).

Em geral, os micronutrientes também são mais elevados nos sítios sob cobertura vegetal de restinga (Tab. 3). Os solos da ilha de Algodoal/ Maiandeua são arenosos (Amaral. 1998). Solos arenosos podem conter contém mais metais pesados que os solos argilosos, dependendo do seu material de origem. Solos litorôneos podem conter maiores contribuições de metais pesados trazidos pela água do mar carreados de outras partes da costa. A cobertura vegetal também pode estar contribuindo, pois nestas áreas existe uma vegetação que apresenta um teor de $\mathrm{Cu}$ mais elevado em suas folhas que é denominada de vegetação cuprífera (informação verbal. Dr. Mário Jardim CBO/MPEG). Os metais, também, podem estar formando quelatos com a MOS.

Em geral, ocorrem maiores teores de AF em relação aos AH (Figs 1 e 2), sendo que existe uma tendência dos $\mathrm{AF}$ aumentarem com o decréscimo da profundidade (Guedes \& Ruivo, 1999). Os solos nos sítios 4 e $4 \mathrm{~A}$ apresentam teores de ácidos hímicos mais elevados em relação aos demais e

Tabela 2. Valores máximos e mínimos do $\mathrm{pH}$ e teores dos macro e micronutrientes na matéria orgânica leve (MOL), na manta orgânica (MO) e no solo

\begin{tabular}{|c|c|c|c|c|c|c|}
\hline \multirow[t]{2}{*}{ Elementos } & \multicolumn{2}{|c|}{ MOL * } & \multicolumn{2}{|c|}{ MO } & \multicolumn{2}{|c|}{ Solo* } \\
\hline & $\operatorname{Max}$ & $\mathrm{Min}$ & Max & $\mathrm{Min}$ & $\operatorname{Max}$ & Min \\
\hline $\mathrm{pH}$ & - & - & - & - & $5,9(3)$ & $4,5(4)$ \\
\hline $\mathrm{Ca}$ & $11,0(6)$ & $1,5(3)$ & $1,2(6)$ & $1,8(3)$ & $10(3)$ & $0,5(3)$ \\
\hline K & $0,14(3)$ & $0,01(5)$ & $0,34(3)$ & $0,01(5)$ & $0,87(3)$ & $0,08(5 a)$ \\
\hline $\mathrm{Mg}$ & $4,5(3)$ & $1,0(5 a)$ & $24(3)$ & $2,5(5)$ & $1,3(3)$ & $0,18(5)$ \\
\hline $\mathrm{Na}$ & - & - & - & - & $7,0(3)$ & $<0,5(4, \ldots, 6)$ \\
\hline C & - & - & - & - & $7,0(4)$ & $2,5(3)$ \\
\hline$P$ & - & - & - & - & $9,5(5)$ & $4,0(5 a)$ \\
\hline $\mathrm{Al}$ & - & - & - & - & $1,2(4)$ & $0,15(5 a)$ \\
\hline $\mathrm{Fe}$ & $22(3)$ & $1(4)$ & $34(5)$ & $0,15(4)$ & - & - \\
\hline \multirow[t]{2}{*}{$\mathrm{Zn}$} & $36(4 a)$ & $5(4)$ & $180(5)$ & $15(6)$ & - & - \\
\hline & $30(4$ e 5$)$ & $10(4$ e $4 a)$ & $11(4$ e 5$)$ & $5(4)$ & - & - \\
\hline
\end{tabular}

Obs: ( ) sitios; ${ }^{*}$ profundidade de $0-5 \mathrm{~cm}$; unidades na MOL/ MO: $\mathrm{Ca}, \mathrm{K}, \mathrm{Mg}, \mathrm{Cu}, \mathrm{Zn}, \mathrm{Fe}(\mathrm{mg} / \mathrm{kg}) ;$ unidades no solo: $\mathrm{Ca}, \mathrm{Mg}, \mathrm{K}, \mathrm{Na}, \mathrm{Al}\left(\mathrm{cmolc}_{\mathrm{dm}}\right)^{3}, \mathrm{C}(\mathrm{g} / \mathrm{kg}), \mathrm{P}\left(\mathrm{mg} / \mathrm{dm}^{3}\right)$. 
Tabela 3. Produção de matéria orgânica leve (MOL) e manta orgânica (MO); caracteristicas químicas do solo nos sítios estudados

\begin{tabular}{|c|c|c|c|c|c|c|c|c|c|c|c|c|}
\hline PROF & MOL & M.O' & $C^{2}$ & $\mathrm{~N}^{2}$ & $\mathrm{CTC}^{2}$ & $s^{2}$ & $p^{2}$ & $\mathrm{pH}$ & $v^{2}$ & $\mathrm{~m}^{2}$ & Solo & Vegetação \\
\hline \multirow{2}{*}{$-\mathrm{cm}-$} & \multicolumn{2}{|c|}{$\cdots \cdots \cdot g$} & -- lg. $\mathrm{Kg}$ & +1. & -mmol.kg & '- & $\mathrm{mg}_{\mathrm{dm}}^{-3}$ & |н20) & \multicolumn{3}{|c|}{$\ldots \% \ldots$} & \\
\hline & \multicolumn{12}{|c|}{ Sitio 3} \\
\hline 0.5 & 15,18 & & & & & & & & & & NEOSSOLO FLÚVICO Sódico & Campos Salinos \\
\hline $5 \cdot 10$ & 1,27 & 326.4 & 7,3 & 0,5 & 110,0 & 83,0 & 7 & 3,4 & 75 & 11 & & \\
\hline \multirow[t]{2}{*}{$10-20$} & 0,64 & & & & & & & & & & & \\
\hline & \multicolumn{12}{|c|}{ Sitio 4} \\
\hline 0.5 & 39,6 & & & & & & & & & & ESPODOSSOLO HIDROMÓRFICO & Restinga Arbustiv a Aberta \\
\hline $5-10$ & 9,89 & 642,69 & 23,2 & 1,4 & 132,0 & 43,0 & 11 & 5,0 & 33 & 7 & & \\
\hline \multirow[t]{2}{*}{$10-20$} & 4.09 & & & & & & & & & & & \\
\hline & \multicolumn{12}{|c|}{ Sítio $4 \mathrm{~A}$} \\
\hline 0.5 & 19,79 & & & & & & & & & & ESPODOSSOLO HIDROMÓRFICO & Restinga Arbustiv a Aberta \\
\hline $5 \cdot 10$ & 5,8 & 546,48 & 13,7 & 0,9 & 180,7 & 163,7 & 19 & 5,5 & 91 & 0 & & \\
\hline \multirow[t]{2}{*}{$10-20$} & 3,38 & & & & & & & & & & & \\
\hline & \multicolumn{12}{|c|}{ Sítio 5} \\
\hline 0.5 & 19,53 & & & & & & & & & & ARGISSOLO AMARELO Distróf ćco & Vegetação Secundária (capoeira) \\
\hline $5-10$ & 1,93 & 356,69 & 7,2 & 0,4 & 42,2 & 11,2 & 2 & 4,7 & 26 & 26 & & \\
\hline \multirow[t]{2}{*}{$10 \cdot 20$} & 0,87 & & & & & & & & & & & \\
\hline & \multicolumn{12}{|c|}{ Sitio $5 \mathrm{~A}$} \\
\hline 0.5 & 14,9 & & & & & & & & & & NEOSSOLO FLÚVICO Distróf ico & Vegetação Secundária (capoeira) \\
\hline $5-10$ & 2,73 & 442,08 & 14,5 & 0,8 & 47,9 & 15,9 & 2 & 4,4 & 20 & 20 & & \\
\hline \multirow[t]{2}{*}{$10-20$} & 2,58 & & & & & & & & & & & \\
\hline & \multicolumn{12}{|c|}{ Sitio 6} \\
\hline $0-5$ & 16,99 & & & & & & & & & & NEOSSOLO FLÚVICO Distrófico & Vegetaçāo Secundária (capoeira) \\
\hline $5-10$ & 2,8 & 264,36 & 19,4 & 1,1 & 99,2 & 55,2 & 5 & 4,7 & 56 & 5 & & \\
\hline $10-20$ & 2,76 & & & & & & & & & & & \\
\hline
\end{tabular}


$\mathrm{pH}$ variando de fortemente a moderadamente ácido. Nos sítios $5,5 \mathrm{~A}$ e 6 , os valores dos ácidos fúlvicos não diferem significativamente entre sim, porém são mais altos do que os verificados nos sítios 4 e $4 \mathrm{~A}$. Naqueles solos o $\mathrm{pH}$ apresenta-se extremamente ácido (Tab. 4; Figs 1 e 2).

Estudos indicam que quanto mais ácidos os solos maiores teores de ácidos fúlvicos são encontrados. Martins et al. (1989), encontraram em solos do nordeste paraense, uma relação entre maior acidez e a presença de maiores teores de ácidos fúlvicos no solo. Isto pode estar ligado a qualidade da matéria orgânica (estrutura e composição química das substâncias húmicas).

Não foi verificada diferença significativa entre os componentes químicos analisados na fração ácido fúlvico (AF), com exceção do sítio 4 (Espodossolo) que apresentou os menores teores de $\mathrm{AF}$, entre todos os solos. Numericamente é neste solo que ocorre também os maiores teores de C no AF (Tab. 4).
Os sítios do Espodossolo, principalmente o 4 , foram os que apresentaram produção de biomassa vegetal (MO e MOL), teores de nutrientes (S, N, P e C) e ácidos húmicos mais elevados em relação aos demais. Nestes sítios estima-se que a mineralização seja maior que a decomposição da matéria orgânica. Por outro lado, o Neossolo Flúvico Sódico (3) e Neossolo Flúvico (6) apesar de serem de caracter eutrófico (caracter dado mais pelo elevado teor de $\mathrm{Na}$, do que pela presença dos demais nutrientes, que concorre para elevar a saturação em bases (Amaral, 1998)) apresentam baixa produção de biomassa vegetal e baixos teores de ácidos húmicos (6). O Espodossolo localiza-se em um relevo que varia de plano a suavemente ondulado. Por outro lado, o Neossolo Flúvico Sódico esta posicionado na parte mais baixa e plana da toposeqüência (Fig. 1), sendo periodicamente inundado e salinilizado pela influência da água do mar. A cobertura vegetal, a posição

Tabela 4. Valores médios de alguns elementos da composição química do Ácido Fúlvico

(AF) extraído dos diferentes tipos de solos da APA de Algodoal - PA.

\begin{tabular}{|c|c|c|c|c|c|}
\hline \multirow[t]{2}{*}{ Sítio } & \multirow[t]{2}{*}{ Solos } & \multicolumn{4}{|c|}{ Teores e Composição do AF } \\
\hline & & $\mathrm{AF}$ & $\mathrm{CO}$ & СТC & AT \\
\hline & & $(\%)$ & $\left(\mathrm{g} / \mathrm{Kg}^{-1}\right)$ & \multicolumn{2}{|c|}{$\left(\mathrm{cmolc} / \mathrm{dm}^{-1}\right)$} \\
\hline $5 a$ & NEOSSOLO FLÚVICO & $99,0 \mathrm{a}$ & $3,11 \mathrm{a}$ & $5,94 \mathrm{a}$ & $0,90 \mathrm{~b}$ \\
\hline 6 & NEOSSOLO FLÚVICO & $99,0 \mathrm{a}$ & $3,16 \mathrm{a}$ & $3,22 a$ & $0,51 \mathrm{a}$ \\
\hline 5 & ARGILOSOLO AMARELO Distrófico & $98,8 \mathrm{ab}$ & $3,52 a$ & $4,91 \mathrm{a}$ & $0,27 a$ \\
\hline 4 & ESPODOSSOLO HIDROMÓRFICO & $98,2 \mathrm{ab}$ & $3,17 \mathrm{a}$ & $4,84 a$ & $0,21 \mathrm{a}$ \\
\hline $4 a$ & ESPODOSSOLO HIDROMÓRFICO & $97,7 \mathrm{~b}$ & $3,90 \mathrm{a}$ & $3,86 \mathrm{a}$ & $0,44 \mathrm{a}$ \\
\hline
\end{tabular}

Obs: Médias seguidas de mesma letra, na vertical, não diferem estatisticamente pelo teste de Student ao nível de $5 \%$ de probabilidade; CO: carbono orgânico total; CTC: capacidade de troca de cátions, AT: acidez total 
topográfica e a influência da maré aparecem, neste caso, como os principais fatores de diferenciação dos solos.

\section{Conclusões}

Os sítios do Espodossolo foram os de maior produção de matéria orgânica lábil,

Os maiores teores de ácidos fúlvicos estão relacionados a acidez do solo e a baixa qualidade da matéria orgânica.

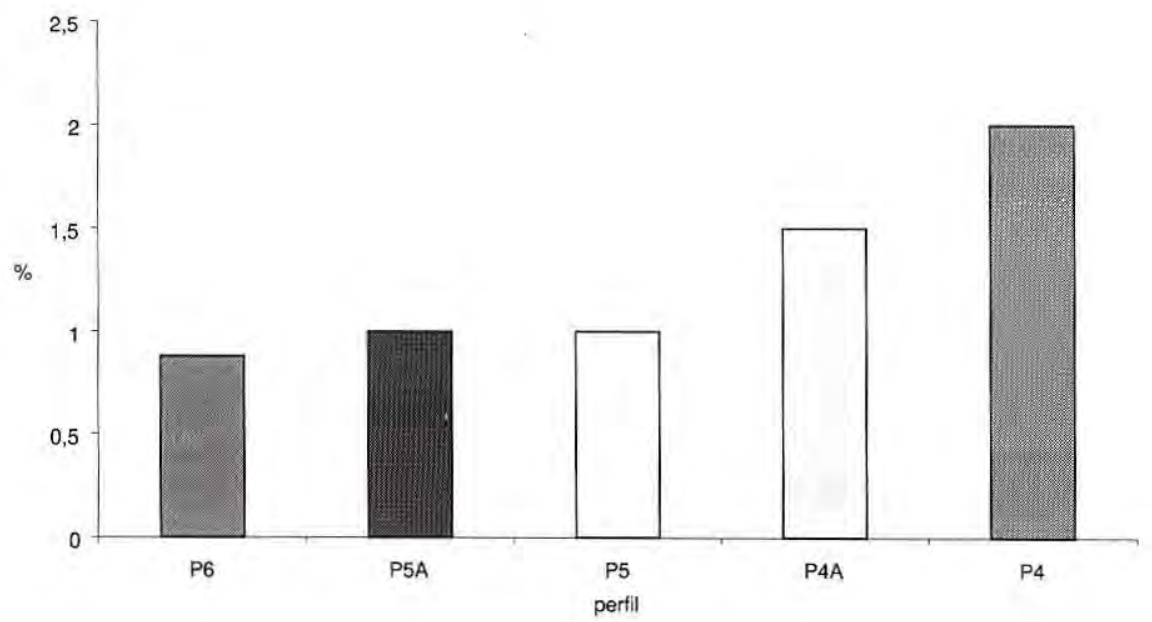

Figura 1: Teores de ácido húmico no solo: média ponderada à $20 \mathrm{~cm}$

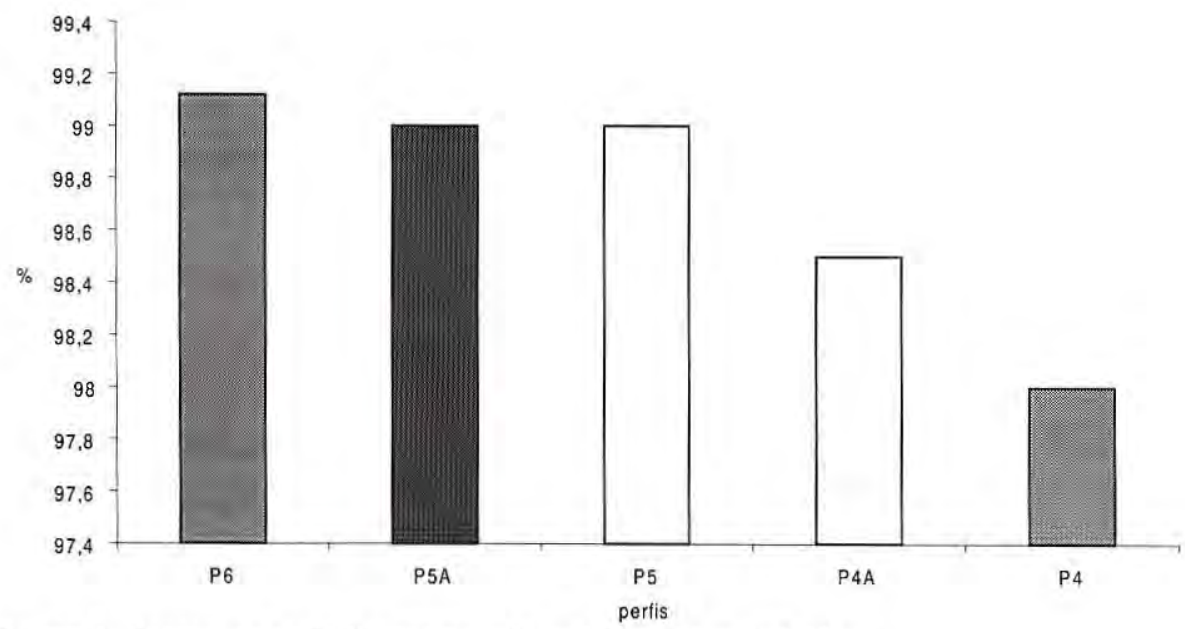

Figura 2. Teores de ácido fúlvico no solo: média ponderada à $20 \mathrm{~cm}$ 
A maior parte do carbono total do solo vem das substâncias húmicas fornecido a ele pela fração ácido fúlvico.

\section{Bibliografia citada}

Amaral, I.G. 1998. Caracterização de solos de uma toposseqüencia na Ilha de Maiandeua$P A$. Belém: Faculdade de Ciências Agrárias do Pará, 86p. Dissertação (Mestrado em Agronomia). 86p.

Amaral, I.G.; Rodrigues, T.E.; Senna, C. ; Ruivo, M.L.P. 2000. Caracterização Pedológica de uma toposseqüência em ambiente litorâneo. In: Mangrove 2000, CD-Room dos Artigos Completos, Recife.

Anderson, J.M., Flanagan, P.W. 1994. Biological processes regulating organic matter dynamics in tropical soils. In: Doran, J.W., Coleman, D.C., Bezdicek, D.F., Stewart, B.B., (Eds.) Defining soil quality for sustainable environmental. Madison, SSCA/ ASA, p.97-123. (SSCA Special Publication Number, 35).

Bastos, M. de N. do C. 1996. Caracterização das formações vegetais da restinga da Princesa, Ilha de Algodoal-Pará. Belém: Universidade Federal do Pará, 261p. Tese (Doutorado em Ciências Biológicas).

Ceretta, C.A. 1996 Substâncias húmicas do solo no contexto do plantio direto e da sustentabilidade. In: I Encontro Brasileiro sobre Substâncias Húmicas, Anais, Belém.

Costa, C.A.C. 1992. Estudo de Adsorção e Remoção de Substâncias Húmicas por Sulfato de aluminio em Águas de Abastecimento. Sào Carlos-SP, Universidade Federal de São Carlos/ Departamento de Química), 329p, (Tese de Doutorado).

Duda, G.P., Campello, E.F.C., Mendonça, E.S., Loures, J.L., Mpanzo, D. 1999. Avaliação da dinâmica de matéria orgânica do solo para caracterização de áreas degradadas. Viçosa. Revista Brasileira de Ciência do Solo,

Embrapa. 1997. Manual de análises químicas. EMBRAPA, Rio de Janeiro, 212p.
Gregorich, E.G.; Carter, M.R.; Angers, D.A; Monreal, C.M.; Ellert, B.H. 1994. Towardsa minimum data set to assesoil organic matter quality in agricultural soils. Canadian Journal of Soil Science, 74:367-385.

Guedes, A. L. C.; Ruivo, M. L. P. 1999. Caracterização de substâncias húmicas em uma toposequeencia na Ilha de Algodoal/ Maiandeua-PA. IN: Seminário de Iniciação Cientifica FCAP e EMBRAPA, Resumos Expandidos, Belém, p. 238-239.

Martins, P.F.S., Cerri, C.C. , Andreux, F., Volkoff, B. 1989. O solo de um ecossistema natural de floresta localizado na Amazônia oriental. II. fracionamento da matéria orgânica do horizonte A. Boletim do Museu Paraense Emilio Goeldi. Série Ciências da Terra, Belém, 1(2):79-89.

Prost, M.T.R. da C. 1994. O litoral nordeste do estado do Pará: dinâmica atual e aplicação do sensoriamento remoto. Municipios de Marapanim, Maracaná e Salinópolis, Relatório Final, Belém. MCT/ CNPQ/MPEG, 55p. (Programa de Estudos Costeiros)

Ruivo, M.L.P. 1998. Vegetação e caracteristicas do solo como indicadores de reabilitação de áreas mineradas na Amazônia Oriental. Viçosa: UFV, 101p. (Tese de Doutorado em Solos e Nutrição de Plantas).

Ruivo, M.L.P.; Amaral, I.G.; Guedes, A.L.S; Ribeiro, E.L.C. 2000. Caracterização e produção de matéria orgânica (lábil e estável) em uma toposseqüência na Ilha de Algodoal/Mainadeua, nordeste do estado do Pará. In: Mangrove 2000, CD-Room dos Artigos Completos, Recife.

Sales, M. E. da C. 2000. Decomposição de Folhas de espécies de mangues na região de São Caetano de Odivelas, costa nordeste do Pará. Belém: Faculdade de Ciências Agrárias do Pará, 54p. Dissertação (Mestrado em Agronomia).

Theng, B. K. G.; Tate, K. R.; Sollins, P. 1989. Constituents of organic matter imterperate and tropical soils. In: Coleman, D. C. ; Oades, J. M.; Uehara, G. (eds) Dynamics of soil organic matter in tropical ecosys- 
tems. Hawaii, Niftal project, p.5-32.

Toledo, A .P.P. 1976. Contribuição ao Estado Físico-químico do ácido húmico extraido de sedimento. Instituto de Química da Universidade de São Paulo. São Paulo. (Dissertação de Mestrado). 88p.

Zech, W., Senesi, N., Guggenberg G., Kaiser, K., Lehmann, J., Miano, T. M., Miltener, A, Schroth, G. 1997. Factors controlling humification and mineralization of soil organic matter in the tropics. Geoderma, Amsterdam, 79:117-161.

Aceito para publicação em 18/04/2002 